Check for updates

Cite this: Mater. Adv., 2021, 2, 2068

Received 11th January 2021, Accepted 16th February 2021

DOI: $10.1039 / \mathrm{d} 1 \mathrm{ma} 00021 \mathrm{~g}$

rsc.li/materials-advances

\title{
Ge nanocrystals tightly and uniformly distributed in a carbon matrix through nitrogen and oxygen bridging bonds for fast-charging high-energy-density lithium-ion batteries $\dagger$
}

\author{
Jiayang Li, ${ }^{a}$ Zhenwei $\mathrm{Li}^{\mathrm{b}}$ and Meisheng Han (D) *ac
}

\begin{abstract}
Germanium (Ge) has come into the public interest as a high-capacity and high-rate lithium-ion battery anode. However, its unsatisfactory cycling life is caused by its large volume expansion ( 230\%) upon cycling. In order to settle this intractable problem, a highly mesoporous $\mathrm{Ge} / \mathrm{C}$ nanocomposite, in which Ge nanocrystals ( $20 \mathrm{~nm}$ ) are evenly dispersed into a N,O co-doped carbon matrix, can be prepared via the pyrolysis of a mixture of bis[2-carboxyethylgermanium(Iv)] sesquioxide and dimethylformamide. Vast phase boundaries are induced due to the homogeneously dispersed structure, in which the $\mathrm{N}$ and $\mathrm{O}$ atoms effectively bridge $\mathrm{Ge}$ and $\mathrm{C}$ through $\mathrm{Ge}-\mathrm{O}-\mathrm{C}$ and $\mathrm{Ge}-\mathrm{N}-\mathrm{C}$ bonds, to achieve a highly robust structure and a fast ion transport route. Consequently, the $\mathrm{Ge} / \mathrm{C}$ anode shows a high specific/volumetric capacity of $1607.8 \mathrm{~mA} \mathrm{~h} \mathrm{~g}-1 / 2090.1 \mathrm{~mA} \mathrm{~h} \mathrm{~cm}^{-3}$, prominent cyclability, and a striking rate capability in half cells. Remarkably, a high specific energy density of $481.5 / 358.7 \mathrm{~W} \mathrm{~h} \mathrm{~kg}^{-1}$ at $0.1 / 5 \mathrm{C}$, and a high volumetric energy density of $1019.1 \mathrm{~W} \mathrm{~h} \mathrm{l}^{-1}$ are obtained in full cells with $\mathrm{LiFePO}_{4}$ as the cathode.
\end{abstract}

\section{Introduction}

Owing to a low capacity ${ }^{1}$ and poor rate performance, ${ }^{2}$ a commercial graphite anode cannot meet the requirements of high-energy/power-density lithium-ion batteries (LIBs) for electric vehicles, which need a longer driving mileage and shorter charge time. ${ }^{3,4}$ Consequently, enormous anodes with higher capacity and better rate capability were fabricated in recent years, such as $\mathrm{Si}^{5}{ }^{5}$ $\mathrm{Ge},{ }^{6} \mathrm{Sn},{ }^{7}$ and their corresponding oxides, ${ }^{8-12}$ and transition metal sulfide, ${ }^{13,14}$ etc. Among them, Ge has come to public concern due to its high specific/volumetric capacity of $1624 \mathrm{~mA} \mathrm{~h} \mathrm{~g}^{-1}$ / $8600 \mathrm{~mA} \mathrm{~h} \mathrm{~cm}^{-3},{ }^{15,16}$ and high $\mathrm{Li}^{+}$diffusivity ${ }^{6,17}$ to lead to an amazing rate capability up to $1000 \mathrm{C} .{ }^{18}$ However, Ge experiences a large volume change of $\sim 230 \%$ on cycling to bring about electrode pulverization, and thus cause poor cyclability. ${ }^{6,15-17}$ In order to deal with this intractable problem, a lot of work has been done, such as designing Ge nanostructures, including nanoparticles, ${ }^{6}$ nanofibers,${ }^{16}$ nanotubes,${ }^{19}$ and nanowires ${ }^{20}$ and

\footnotetext{
${ }^{a}$ Advanced Fibers Group, Songshan Lake Materials Laboratory Dongguan, Guangdong 523808, China. E-mail: hanmeisheng@sslab.org.cn

${ }^{b}$ Shenzhen Engineering Lab for Supercapacitor Materials, Shenzhen Key Laboratory for Advanced Materials, School of Material Science and Engineering, Harbin Institute of Technology, Shenzhen, University Town, Shenzhen 518055, China ${ }^{c}$ Beijing National Laboratory for Condensed Matter Physics, Institute of Physics, Chinese Academy of Sciences, Beijing 100190, China

$\dagger$ Electronic supplementary information (ESI) available. See DOI: 10.1039/ d1ma00021g
}

making Ge/C nanocomposites. ${ }^{20-24}$ The latter is regarded to be the most effective way because the added carbon not only improves the electrical conductivity (EC) of Ge, but also acts as a buffer layer/matrix to ease volume expansion. Particularly, the doped carbon can induce vast defects and interfacial chemical bonds between Ge and $\mathrm{C}$ to heighten electrochemical performances. ${ }^{13,23,24}$ The Ge/C nanocomposites mainly include three types. The first type is a core-shell structure in which carbon is coated on the surface of Ge nanostructures. ${ }^{20-22}$ For example, a Ge/graphene nanocomposite was fabricated by growing fewlayered graphene on Ge nanowires with a diameter of $\sim 43 \mathrm{~nm}$ using chemical vapor deposition and delivered a high capacity of $1210 \mathrm{~mA} \mathrm{~h} \mathrm{~g}^{-1}$ after 200 cycles, with a capacity retention of $95 \%$ at a current density of $0.6 \mathrm{~A} \mathrm{~g}^{-1}$ and $363 \mathrm{~mA} \mathrm{~h} \mathrm{~g}^{-1}$ at $24 \mathrm{~A} \mathrm{~g}^{-1} \cdot{ }^{20} \mathrm{~A}$ $\mathrm{Ge} @ \mathrm{C} /$ graphene oxide nanocomposite was synthesized by making core-shell Ge@C nanoparticles into a graphene oxide film, which showed a high capacity of $940 \mathrm{~mA} \mathrm{~h} \mathrm{~g}{ }^{-1}$ at $0.05 \mathrm{~A} \mathrm{~g}^{-1}$ after 50 cycles and $380 \mathrm{~mA} \mathrm{~h} \mathrm{~g}{ }^{-1}$ at $3.6 \mathrm{~A} \mathrm{~g}^{-1}$. ${ }^{21}$ The second type is where Ge nanoparticles are confined on porous carbon. ${ }^{17,23}$ For example, by confining Ge quantum dots in a porous N-doped carbon framework using a template-confined route, in which Ge-O-C and Ge-C bonds were formed, a high capacity of $1160 \mathrm{~mA} \mathrm{~h} \mathrm{~g}{ }^{-1}$ after 200 cycles at $1 \mathrm{~A} \mathrm{~g}^{-1}$ was obtained. ${ }^{17}$ By encapsulating Ge nanoparticles into a $\mathrm{N}$-doped carbon nanotube with a size of $80-200 \mathrm{~nm}$, a high capacity of $1080 \mathrm{~mA} \mathrm{~h} \mathrm{~g}{ }^{-1}$ after 1200 cycles with a capacity retention of $\sim 90 \%$ at $0.8 \mathrm{~A} \mathrm{~g}^{-1}$ was obtained. ${ }^{23}$ The last type is where $\mathrm{Ge}$ 
nanoparticles are uniformly dispersed into the carbon matrix. ${ }^{24}$ For instance, Ge/C nanospheres with a size of 300-600 nm were obtained by a sol-gel method, and exhibited a high capacity of $684 \mathrm{~mA} \mathrm{~h} \mathrm{~g}^{-1}$ after 200 cycles with a capacity retention of $89.6 \%$ at $0.2 \mathrm{~A} \mathrm{~g}^{-1}$ and $472 \mathrm{~mA} \mathrm{~h} \mathrm{~g}{ }^{-1}$ at $2 \mathrm{~A} \mathrm{~g}^{-1} \cdot{ }^{24}$ Although the $\mathrm{Li}^{+}$ storage performances of $\mathrm{Ge}$ in the above-mentioned $\mathrm{Ge} / \mathrm{C}$ nanocomposites have been strengthened, a higher capacity and longer cycle life are needed in practical applications, especially at a high current density. Additionally, their preparation processes are too complex and cumbersome to fulfil the vital importance of an uncomplicated method for obtaining high-capacity, high-rate, and long-cycling-life Ge/doped-C nanocomposites at different current densities.

Here, based on these problems, we fabricate a $\mathrm{Ge} / \mathrm{C}$ nanocomposite via a practical one-step pyrolysis of a mixture of bis[2-carboxyethylgermanium(Iv)] sesquioxide (BS, $\mathrm{C}_{6} \mathrm{H}_{10} \mathrm{Ge}_{2} \mathrm{O}_{7}$ ) and dimethylformamide (DMF, $\mathrm{C}_{3} \mathrm{H}_{7} \mathrm{ON}$ ) in a sealed vessel. The Ge/C nanocomposite with a highly mesoporous structure comprises Ge nanocrystals $(\sim 20 \mathrm{~nm})$ homogeneously and tightly embedded into a carbon matrix through chemical bridge bonding of $\mathrm{N}$ and $\mathrm{O}$ atoms. These characteristics endow the $\mathrm{Ge} / \mathrm{C}$ nanocomposite with a high capacity, an unprecedented cyclability, and a prominent rate capability as the LIB anode in half/full cells. Markedly, the full cell with a $\mathrm{LiFePO}_{4}$ (LFP) cathode represents a high specific energy density of $481.5 \mathrm{~W} \mathrm{~h} \mathrm{~kg}^{-1}$ at $0.1 \mathrm{C}$ and $358.7 \mathrm{~W} \mathrm{~h} \mathrm{~kg}^{-1}$ at $5 \mathrm{C}$, and a high volumetric energy density of 1019.1 $\mathrm{W} \mathrm{h} \mathrm{L}^{-1}$.

\section{Experimental section}

\section{Synthesis of Ge/C nanocomposites}

A vessel containing $0.4 \mathrm{~g}$ BS (Tokyo Chemical Industry) and $0.4 \mathrm{~g}$ DMF was sealed in an Ar-filled glove box and placed in a tube furnace, which was heated to $650{ }^{\circ} \mathrm{C}$ for $2 \mathrm{~h}$ at $10{ }^{\circ} \mathrm{C} \mathrm{min}^{-1}$ with $\mathrm{Ar}$ to obtain the Ge/C nanocomposites with $\mathrm{N}$ and $\mathrm{O}$ atoms.

\section{Characterizations}

A scanning electron microscope (SEM, Hitachi S-4700), transmission electron microscope (TEM) with an energy dispersive spectrometer (EDS), X-ray diffractometer (XRD), Raman spectrometer, X-ray photoelectron spectrometer (XPS), thermogravimetric analyzer (TGA), elemental analyzer, and an accelerated surface area and porosimetry system were used to probe the obtained materials.

\section{Electrochemical measurements}

In half cells, anode electrodes containing $80 \mathrm{wt} \%$ active materials, $10 \mathrm{wt} \%$ acetylene black, and $10 \mathrm{wt} \%$ polyvinylidene fluoride, together with electrolyte (DoDoChem), $\mathrm{Li}$ foil, and a 2400 membrane, were assembled into 2032 coin-type cells in an Ar-filled glove box. In full cells, cathode electrodes consist of $94 \mathrm{wt} \%$ LFP (MTI Corporation), $3 \mathrm{wt} \%$ acetylene black, and $3 \mathrm{wt} \%$ polyvinylidene fluoride. A N/P ratio of about 1.1 is achieved by using a Ge/C of $2.2 \mathrm{mg} \mathrm{cm}{ }^{-2}$ to match a LFP of $18.3 \mathrm{mg} \mathrm{cm}^{-2}$. Prior to their assembly, the anode electrodes were first cycled for three cycles in a half cell to increase their first Coulombic efficiency (CE). The electrochemical performances of all the cells including cycling/rate curves, cyclic voltammetry (CV) curves, and electrochemical impedance spectroscopy (EIS) were tested using a Land battery testing system and an electrochemical workstation. The models of the testing equipment in the previous two sections are the as in our previous reports. ${ }^{12,13}$

\section{Results and discussion}

As described in the section 2.1, the synthesis process of the $\mathrm{Ge} / \mathrm{C}$ nanocomposite only requires one-step high-temperature pyrolysis in a sealed system. Clearly, the Ge/C nanocomposite

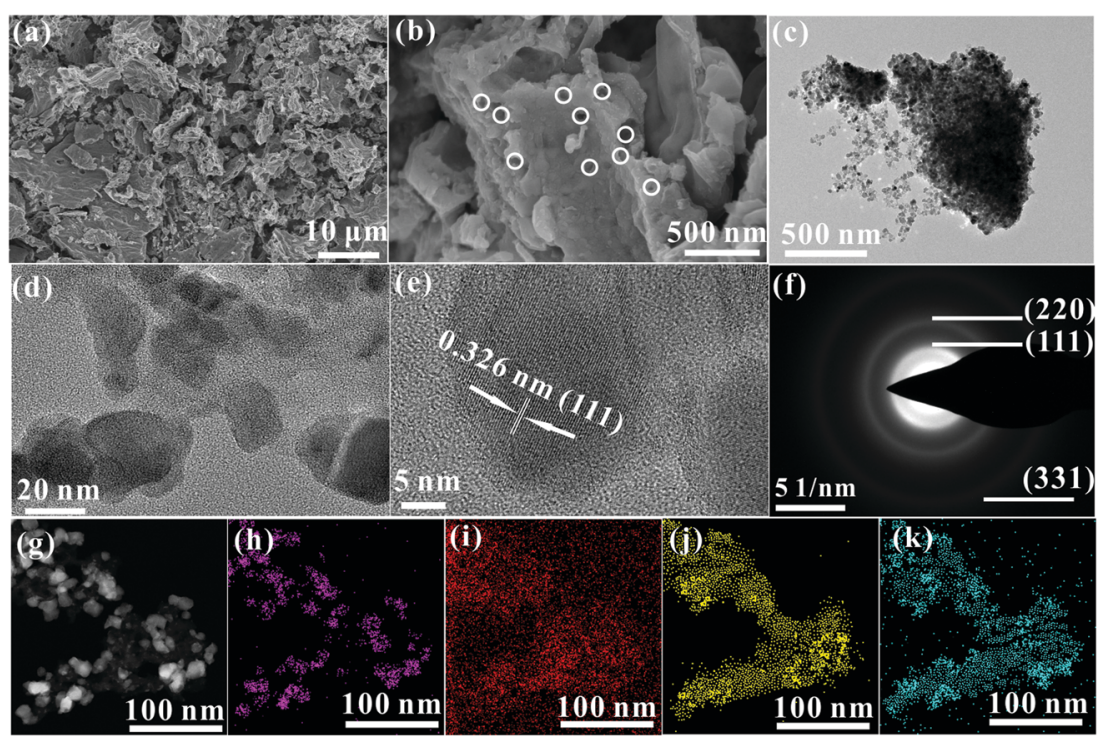

Fig. 1 (a and b) SEM images, (c-e) TEM images, (f) SAED pattern, (g) HAADF image and its corresponding EDS elemental mapping images of Ge (h), C (i), $N(j)$, and $O(k)$. 
cannot be synthesized in an open system due to evaporation of DMF and loss of decomposition products of BS. Differently, the evaporation and decomposition products can be retained in the sealed system to induce high vapor phase pressure to advance gaseous products to transfer into solid substances. ${ }^{13}$ The obtained Ge/C shows a bulk morphology with porous structure marked as white circles (Fig. 1a and b), in which abundant nanocrystals with an average size of about $20 \mathrm{~nm}$ are dispersed into carbon matrix (Fig. 1c and d). The spacing of $0.326 \mathrm{~nm}$ between adjacent lattice fringes corresponds to the (111) crystal plane of Ge (Fig. 1e) to imply the formation of Ge nanocrystals. Debye-Scherrer ring patterns of (111), (220), and (331) crystal planes of $\mathrm{Ge}$ appear in the selected area electron diffraction (SAED) pattern (Fig. 1f) to further confirm the presence of Ge crystals. Besides this, the Ge, O, C, and $\mathrm{N}$ elements are evenly distributed in the nanocomposite, shown in the high angle annular dark field (HAADF) image and its corresponding EDS elemental mapping images (Fig. 1g-k). The results confirm that Ge nanocrystals are evenly distributed into a N,O co-doped carbon matrix, which is conducive to $\mathrm{Li}^{+}$storage.

A series of diffraction peaks at 27.3, 45.3, 53.7, 65.9, and $72.8^{\circ}$ (Fig. 2a) correspond to (111), (220), (311), (400), and (331) crystal planes, respectively, of Ge (JCPDS\#04-0545) to further determine the existence of Ge crystals. The broad peak at $12-39^{\circ}$, an indicator of an amorphous structure, is ascribed to an amorphous carbon matrix. Three Raman peaks at 300.1,
1346.3, and $1585.9 \mathrm{~cm}^{-1}$ (Fig. 2b) correspond to Ge crystals, and $D$ and $G$ peaks of carbon materials, respectively, to further confirm the existence of Ge and carbon. ${ }^{13,17}$ The high intensity ratio (1.13) of $D$ and $G$ peaks suggests that the carbon contains plentiful defects beneficial for $\mathrm{Li}^{+}$storage. ${ }^{8,10,13}$ Four elements of Ge (11.6 at\%), C (73.2 at\%), N (9.1 at\%), and O (6.1 at\%) (Fig. 2c) appear to imply high doping amounts of 10.3 and $6.9 \%$, respectively, of $\mathrm{N}$ and $\mathrm{O}$ in the carbon matrix. The Ge $3 \mathrm{~d}$ spectrum (Fig. 2d) exhibits three peaks at 29.8, 31.5, and $33.0 \mathrm{eV}$ ascribed to $\mathrm{Ge}-\mathrm{Ge}, \mathrm{Ge}-\mathrm{N}$, and $\mathrm{Ge}-\mathrm{O}$, respectively, to imply the presence of elemental Ge, Ge-N-C, and Ge-O-C. ${ }^{17,25}$ The $\mathrm{C}$ 1s spectrum (Fig. 2e) reveals three peaks at 284.8, 286.1, and $287.2 \mathrm{eV}$ attributed to $\mathrm{C}-\mathrm{C}, \mathrm{C}-\mathrm{N} / \mathrm{C}-\mathrm{O}$, and $\mathrm{C}=\mathrm{O}$, respectively, ${ }^{13,17}$ to confirm the formation of $\mathrm{N}, \mathrm{O}$ co-doped carbon. ${ }^{13}$ The N 1s spectrum (Fig. 2f) shows four peaks at 397.4, 398.5, 400.1, and 401.2 eV contributed by $\mathrm{N}-\mathrm{Ge}$, pyridinic $\mathrm{N}$, pyrrolic $\mathrm{N}$, and graphitic $\mathrm{N}$, respectively, to further demonstrate the formation of Ge-N-C and N-doped C. ${ }^{13,25}$ The $\mathrm{O} 1 \mathrm{~s}$ spectrum (Fig. 3g) shows two peaks at 532.5 and $533.5 \mathrm{eV}$ arising from $\mathrm{C}=\mathrm{O}$ and $\mathrm{C}-\mathrm{O}-\mathrm{Ge}$ bonds, respectively, to further prove the formation of $\mathrm{O}$-doped $\mathrm{C}$ and $\mathrm{Ge}-\mathrm{O}-\mathrm{C}$ bonds. The presence of Ge- $\mathrm{O}-\mathrm{C}$ and $\mathrm{Ge}-\mathrm{N}-\mathrm{C}$ bonds implies that $\mathrm{O}$ and $\mathrm{N}$ atoms tightly bridge $\mathrm{Ge}$ and $\mathrm{C}$. The $\mathrm{Ge} / \mathrm{C}$ was heated in air to attain the mass percentage of N,O co-doped carbon by TGA (Fig. 2h), during which N,O co-doped carbon can be fully oxidated into gases. The mass loss of $33.2 \%$ from $394-586{ }^{\circ} \mathrm{C}$ represents a mass
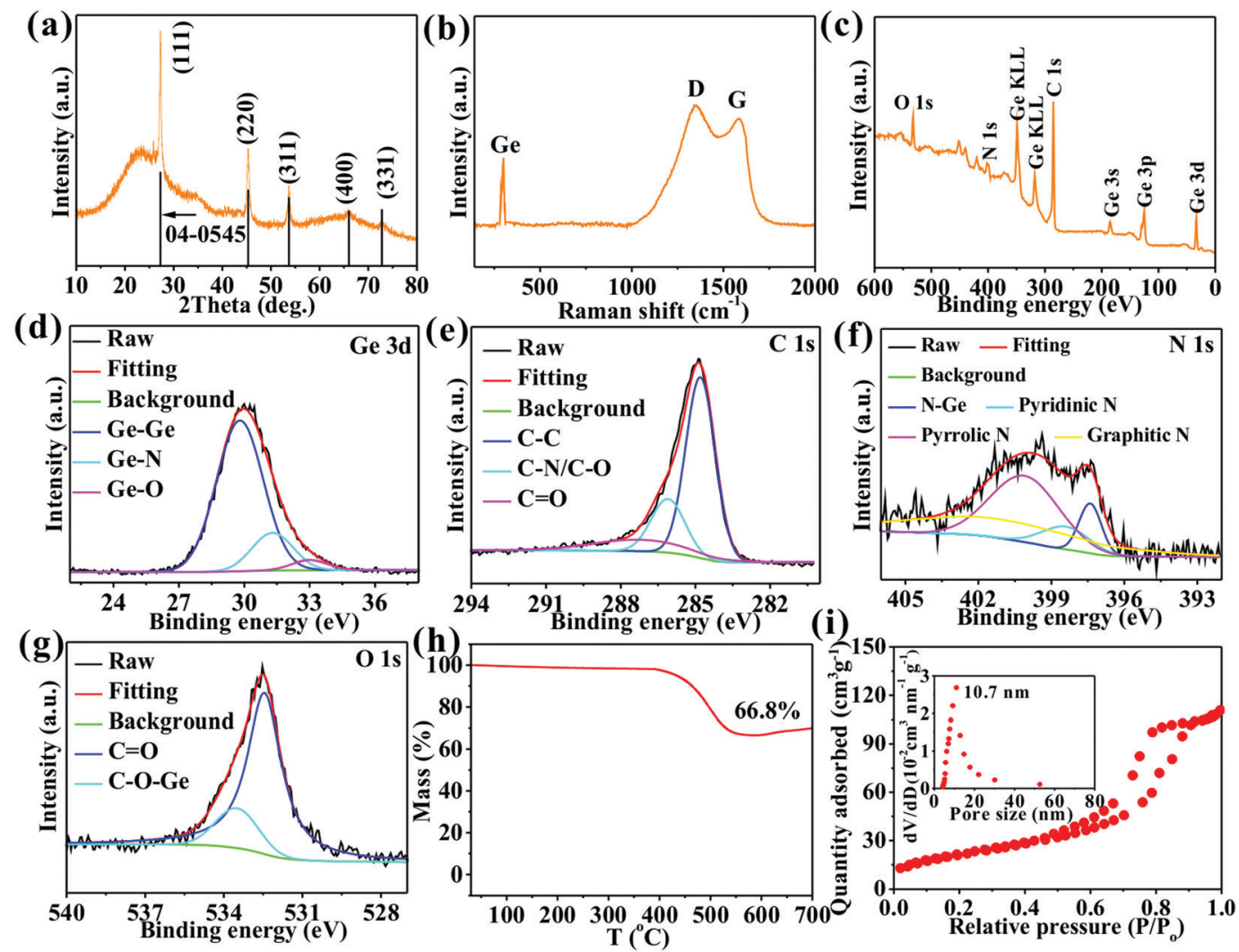

Fig. 2 (a) XRD pattern, (b) Raman spectrum, (c) XPS survey peak, (d-g) XPS spectra of Ge 3d (d), C 1s (e), N 1s (f), and O 1s (g), (h) TG curve, and (i) Nitrogen adsorption-desorption isotherms of $\mathrm{Ge} / \mathrm{C}$. The inset in image $\mathrm{i}$ is the pore size distribution. 

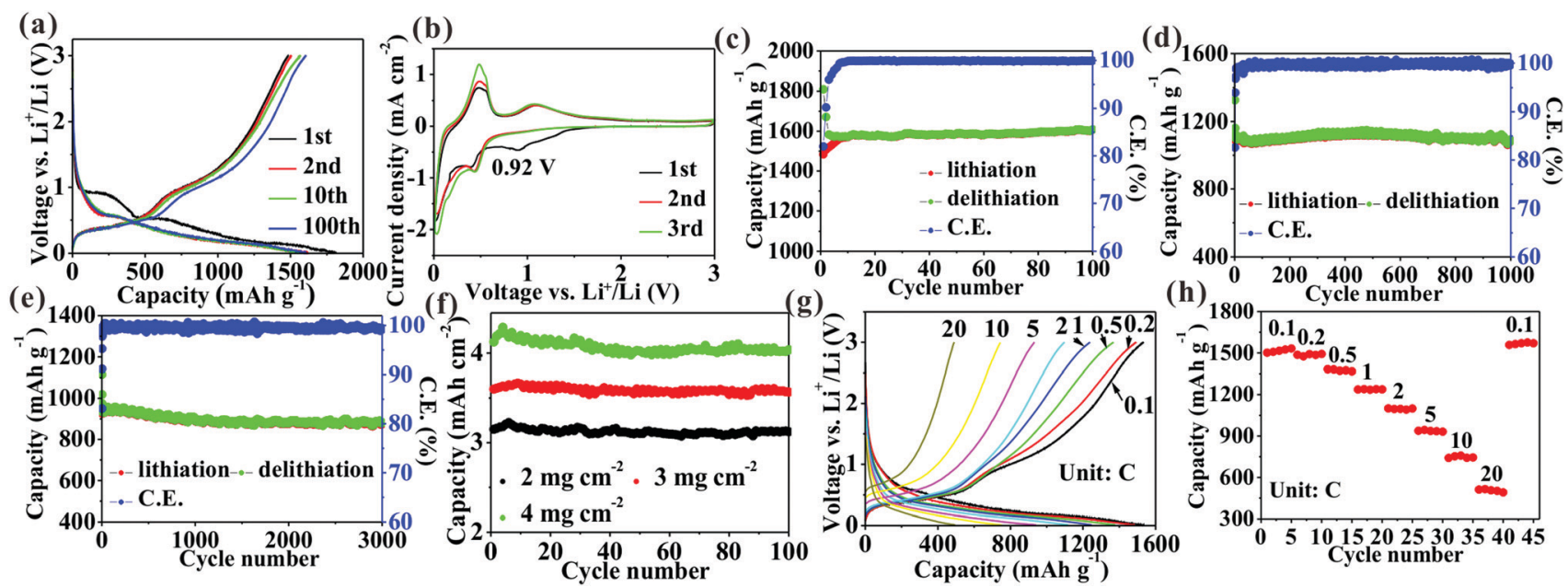

Fig. 3 (a) Voltage profiles at different cycles at $0.1 \mathrm{C}$, (b) CV curves at $0.1 \mathrm{mV} \mathrm{s}^{-1}$, (c-e) Cycling curves at 0.1, 2, and 5C, respectively, (f) Cycling curves at different mass loading at $0.1 \mathrm{C}, \mathrm{g}$ ) voltage profiles at different current densities, and (h) Rate performances of Ge/C. Besides image $\mathrm{f}$, the mass loading is about $1.1 \mathrm{mg} \mathrm{cm}^{-2}$.

percentage of N,O co-doped carbon. The $\mathrm{O} / \mathrm{N} / \mathrm{H}$ and $\mathrm{C} / \mathrm{S}$ elemental analyzers are used to probe mass percentages of $\mathrm{C}, \mathrm{O}$, and $\mathrm{N}$ elements, which are $27.9 \%, 4.0 \%$, and $2.4 \%$, respectively, in agreement with the XPS and TGA results. Additionally, the Ge/C nanocomposite shows a mesoporous structure with a specific surface area of $112.2 \mathrm{~m}^{2} \mathrm{~g}^{-1}$, a pore volume of $0.62 \mathrm{~cm}^{3} \mathrm{~g}^{-1}$, and a well-defined mesopore centered at $10.7 \mathrm{~nm}$ (Fig. 2i), which are favorable for obtaining a high contact area with electrolyte, boosting $\mathrm{Li}^{+}$transport, storing $\mathrm{Li}^{+}$, and accommodating the volume expansion of Ge upon cycling, thus strengthening the electrochemical performances of the nanocomposite. ${ }^{12,26}$

Fig. 3a shows that the first delithiation/lithiation capacities of $\mathrm{Ge} / \mathrm{C}$ nanocomposites at $0.1 \mathrm{C}(1 \mathrm{C}=1.6 \mathrm{~A} / \mathrm{g})$ are $1484.1 /$ $1816.1 \mathrm{~mA} \mathrm{~h} \mathrm{~g}^{-1}$ to obtain a CE of $81.6 \%$. The $18.4 \%$ capacity loss mainly originates from the formation of a solid electrolyte interphase (SEI) layer. ${ }^{17}$ In addition to the first discharge curve, subsequent other curves exhibit a similar $\mathrm{Li}^{+}$storage behavior (Fig. 3a) to imply a good stability of the electrode structure. The CV curves (Fig. 3b) represent a series of cathodic/anodic peaks below $0.5 \mathrm{~V}$ contributed from the alloying/dealloying of Ge. ${ }^{17,27}$ Besides these peaks, in the first curve a cathode peak at $0.92 \mathrm{~V}$ attributed to the formation of SEI layer disappears in subsequent cycles to confirm a good stability of the SEI layer. The average CE in the following description is calculated from the 3 rd to the final cycle. A high specific capacity of $1607.8 \mathrm{~mA} \mathrm{~h} \mathrm{~g}^{-1}$, corresponding to a high volumetric capacity of $2090.1 \mathrm{~mA} \mathrm{~h} \mathrm{~cm}{ }^{-3}$, is obtained after 100 cycles at $0.1 \mathrm{C}$ with a capacity retention of $108.3 \%$ and an average CE of $99.91 \%$ (Fig. 3c). Such a high capacity retention implies a high stability of the electrode structure, which is investigated by observing an electrode change upon cycling by SEM and TEM. After 100 cycles, the Ge/C electrode shows undamaged morphology (Fig. S1a, ESI $\dagger$ ) and a low thickness change of $34.1 \%$ compared with pristine electrode (Figs. S1b and c, ESI $\dagger$ ). Besides, the Ge nanoparticles without pulverization are observed (Fig. S1d-f, ESI $\dagger$ ). These results demonstrate that the electrode structure during cycling is highly stable. However, the average size of Ge nanoparticles changes from pristine $\sim 20$ to $\sim 24 \mathrm{~nm}$ (Fig. S1d and e, ESI $\dagger$ ) and Ge nanoparticles become a disordered structure after cycling (Fig. S1f, ESI $\dagger$ ). The results show that the size of the Ge nanoparticles increases and their structures change from crystalline to amorphous after cycling, which is consistent with the previous reports. ${ }^{28,29}$ Therefore, the increase of electrode thickness is mainly caused by the increase of the size of Ge nanoparticles and the formation of a SEI layer. So the small thickness change is from the structural advantages of $\mathrm{Ge} / \mathrm{C}$ nanocomposites: (i) Ge nanoparticles $(\sim 20 \mathrm{~nm})$ can well accommodate a large strain to lessen volume expansion; ${ }^{8}$ (ii) N,O co-doped carbon as a buffer matrix can effectively constrain volume expansion; ${ }^{13}$ (iii) the nanoscopically and evenly distributed structure can make strain uniformly distribute in the nanocomposite to mitigate volume expansion; ${ }^{7,8,10}$ (iv) the highly mesoporous structure has an accommodation capacity of volume expansion; (v) Bridge effect of $\mathrm{N}$ and $\mathrm{O}$ atoms between Ge and $\mathrm{C}$ via $\mathrm{Ge}-\mathrm{O}-\mathrm{C}$ and $\mathrm{Ge}-\mathrm{N}-\mathrm{C}$ bonds can heighten the interfacial structural stability to ease volume expansion. ${ }^{13,26}$

The cyclability at a high current density is also investigated. High capacities of $1095.3 \mathrm{~mA} \mathrm{~h} \mathrm{~g}{ }^{-1}$ with a $98.8 \%$ capacity retention after 1000 cycles at 2C (Fig. 3d) and $926.8 \mathrm{~mA} \mathrm{~h} \mathrm{~g}^{-1}$ with a $94.4 \%$ capacity retention after 3000 cycle at 5C (Fig. 3e) are obtained. Besides, the cyclability at different mass loadings at $0.1 \mathrm{C}$ are also obtained (Fig. 3f), corresponding to the first reversible areal capacities of $3.2,3.6$, and $4.1 \mathrm{~mA} \mathrm{~h} \mathrm{~cm}^{-2}$ with a capacity retentions of $99.9,99.1$, and $97.6 \%$ after 100 cycles for mass loadings of $2.0,3.0$, and $4.0 \mathrm{mg} \mathrm{cm}^{-2}$, respectively. From these results, the $\mathrm{Ge} / \mathrm{C}$ has a better excellent cyclability whether in a low or high current density, or high areal capacity than those in recent reports of Ge-based anodes (Table S1, ESI $\dagger$ ). It is noteworthy that the reversible capacity $\left(1607.8 \mathrm{~mA} \mathrm{~h} \mathrm{~g}^{-1}\right)$ of Ge/C is higher than that in almost all of previous reports (Table S1, ESI $\dagger$ ), which may be contributed by the high pseudocapacity confirmed in Fig. S2, ESI. $\uparrow$ The contribution percentages of 
pseudocapacitance increase from $30.1 \%$ to $52.5 \%$ with an increasing scanning rate from 0.1 to $1 \mathrm{mV} \mathrm{s}^{-1}$ to confirm the momentous part of pseudocapacitance in capacity, especially at a high scan rate, which may be from additional $\mathrm{Li}^{+}$storage sites, such as defects, ${ }^{26,30}$ phase boundaries, ${ }^{8,26,30,31}$ and the mesoporous structure. ${ }^{12,26,31}$

The rate curves (Fig. 3g) at different current densities show similar lithium ion storage behavior to confirm a good stability of the electrode during rate testing. The reversible capacities of 1531.9, 1493.4, 1368.2, 1238.5, 1099.1, 932.2, 745.3, and $491.7 \mathrm{~mA} \mathrm{~h} \mathrm{~g}^{-1}$ are obtained at $0.1,0.2,0.5,1,2,5,10$, and 20C, respectively (Fig. 3h). When the current reverts to $0.1 \mathrm{C}$, the initial capacity is regained to further confirm a high stability of the electrode structure. The result implies that the $\mathrm{Ge} / \mathrm{C}$ anode possesses an outstanding rate capability higher than that in the most recent reports (Table S1, ESI $\dagger$ ). In order to determine the positive effect of $\mathrm{N}$ and $\mathrm{O}$ atoms bridging $\mathrm{Ge}$ and $\mathrm{C}$ on $\mathrm{Li}^{+}$ storage performances, the $\mathrm{Ge} / \mathrm{C}$ nanocomposite without $\mathrm{N}$ and $\mathrm{O}$ atoms is fabricated by only the pyrolysis of BS. It can be seen that the $\mathrm{Ge} / \mathrm{C}$ nanocomposite in the absence of $\mathrm{N}$ and $\mathrm{O}$ bridging shows a similar morphology to that of the $\mathrm{Ge} / \mathrm{C}$ with $\mathrm{N}$ and $\mathrm{O}$ atoms, but only delivers a capacity of $1472.4 \mathrm{~mA} \mathrm{~h} \mathrm{~g}^{-1}$ with an $82.7 \%$ capacity retention after 100 cycles at $0.1 \mathrm{C}$ and $78.3 \mathrm{~mA} \mathrm{~h} \mathrm{~g}^{-1}$ at 20C (Fig. S3, ESI $\dagger$ ), which are much lower than those of $\mathrm{Ge} / \mathrm{C}$ with $\mathrm{N}$ and $\mathrm{O}$ bridging. Besides this, after 100 cycles, it can be observed that the $\mathrm{Ge}-\mathrm{O}-\mathrm{C}$ and $\mathrm{Ge}-\mathrm{N}-\mathrm{C}$ bonds still exist in the Ge/C nanocomposites (Fig. S4, ESI $\dagger$ ). The results fully confirm that $\mathrm{N}$ and $\mathrm{O}$ atoms closely bridging $\mathrm{Ge}$ and $\mathrm{C}$ considerably enhance the electrochemical performances of the nanocomposite. The carbon matrix is synthesized by only pyrolysis of DMF (Fig. S5, ESI $\dagger$ ). It can be seen that the carbon matrix is amorphous and N,O-codoped and shows a capacity of $614.2 \mathrm{~mA} \mathrm{~h} \mathrm{~g}^{-1}$ at $0.1 \mathrm{C}, 455.2 \mathrm{~mA} \mathrm{~h} \mathrm{~g}^{-1}$ with a $101.1 \%$ capacity retention after 100 cycles at $1 \mathrm{C}$, and $149.8 \mathrm{~mA} \mathrm{~h} \mathrm{~g}^{-1}$ at $20 \mathrm{C}$. The results show that the carbon matrix has a high capacity, a long cyclability, and a good rate capability, which is conducive to the enhancement of lithium-ion storage performances of the hybrid composites.

The prominent rate capability of the $\mathrm{Ge} / \mathrm{C}$ is in connection with its high EC $\left(3.5 \times 10^{3} \mathrm{~S} \mathrm{~m}^{-1}\right)$, low $\mathrm{Li}^{+}$transport resistance, and high $\mathrm{Li}^{+}$diffusion coefficient $\left(D_{\mathrm{Li}^{+}}\right)$, as discussed below. The EIS (Fig. 4a) of the Ge/C at different cycling numbers are fitted to equivalent circuits (Fig. $4 \mathrm{~b}$ and c), where $R_{\mathrm{S}}$ is the electrolyte resistance, $R_{\mathrm{f}}$ the SEI layer resistance, $R_{\mathrm{ct}}$ the charge transfer resistance and $\mathrm{W}$ the Warburg impedance of $\mathrm{Li}^{+}$diffusion. ${ }^{30}$ Upon cycling, the value of $R_{\mathrm{f}}$ is basically unchanged (Table $\mathrm{S} 2$, $\mathrm{ESI} \dagger)$ to further demonstrate the high stability of the SEI layer. Besides this, the reduction of $R_{\mathrm{ct}}$ upon cycling (Fig. $4 \mathrm{a}$ and Table S2, ESI $\dagger$ ) is extremely beneficial for $\mathrm{Li}^{+}$transport kinetics, which is further explored in the EIS after 100 cycles via the relationship between the real impedance $\left(Z_{\text {re }}\right)$ and reciprocal square root of lower angular frequencies $\left(\omega^{-1 / 2}\right)$ (Fig. $\left.4 \mathrm{~d}\right)$. The Warburg impedance coefficient $\left(\sigma_{\omega}\right)$ and $D_{L i+}$ can be achieved based on $Z_{\mathrm{re}}=R_{\mathrm{s}}+R_{\mathrm{f}}+R_{\mathrm{ct}}+\sigma_{\omega} \omega^{-1 / 2}$ and $D_{\mathrm{Li}^{+}}=\left(R T / A F_{2} \sigma_{\omega} C\right)^{2}$, respectively, where $R$ is the gas constant, $T$ is the absolute temperature, $F$ is the Faraday constant, $A$ is the electrode area, and $C$ is the molar concentration of $\mathrm{Li}^{+}{ }^{30}$ The calculated $\sigma_{\omega}$ and $D_{\mathrm{Li}^{+}}$values of the $\mathrm{Ge} / \mathrm{C}$ are $30.2 \Omega \mathrm{S}^{-1 / 2}$ and $3.1 \times 10^{-10} \mathrm{~cm}^{2} \mathrm{~s}^{-1}$, respectively. This low $\sigma_{\omega}$ and high $D_{\mathrm{Li}^{+}}$can markedly boost the $\mathrm{Li}^{+}$diffusion rate to ensure exceedingly good rate capability. The excellent cyclability and rate capability of the $\mathrm{Ge} / \mathrm{C}$ nanocomposite are attributed to its homogeneously dispersed
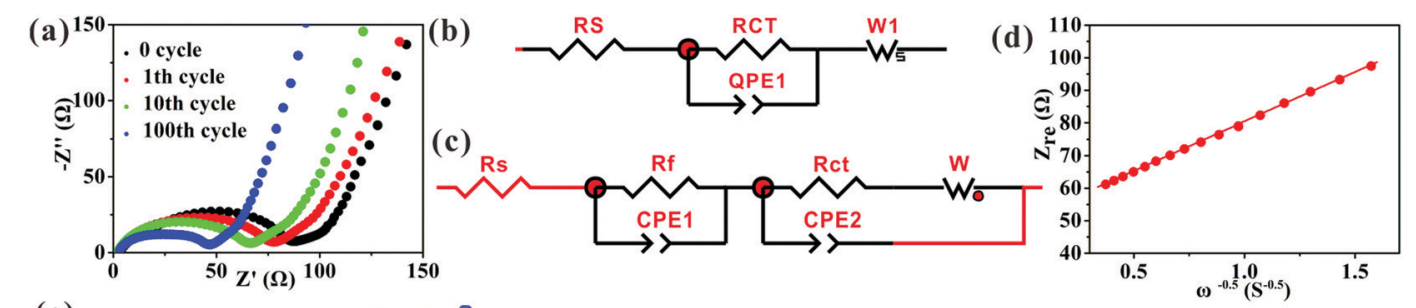

(e)

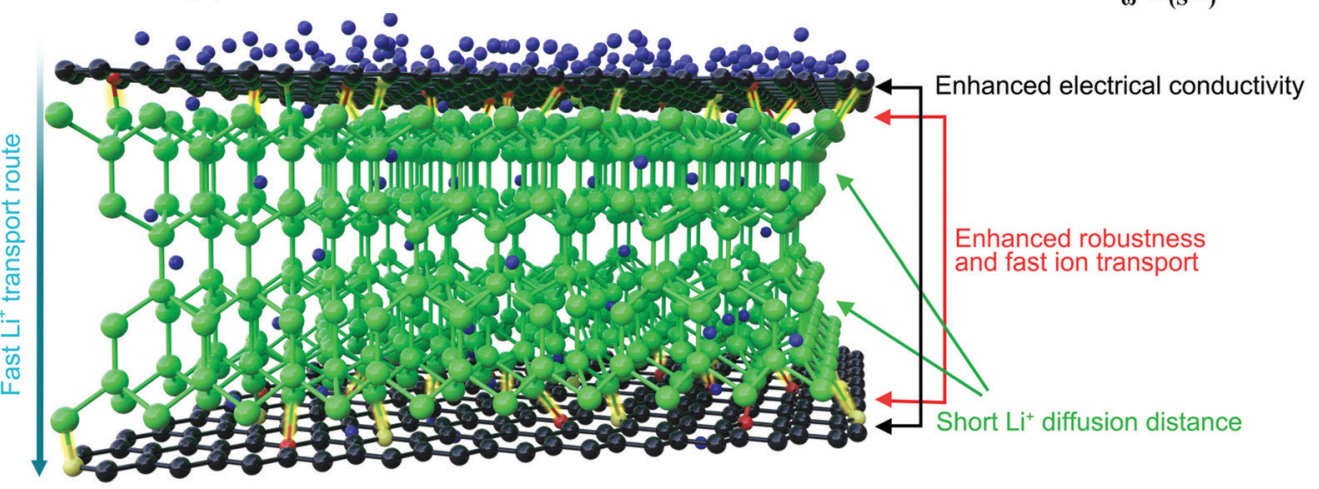

$\mathrm{Ge}$
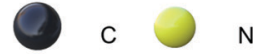

$\mathrm{O}$

$\mathrm{Li}^{+}$

Fig. 4 (a) Nyquist plots before and after cycling, (b and c) Equivalent circuit models before cycling (b) and after cycling (c), (d) Relationship between $Z_{\text {re }}$ with low frequencies after 100 cycles of $\mathrm{Ge} / \mathrm{C}$, and (e) Atomic schematic diagram of microstructure of Ge/C. 

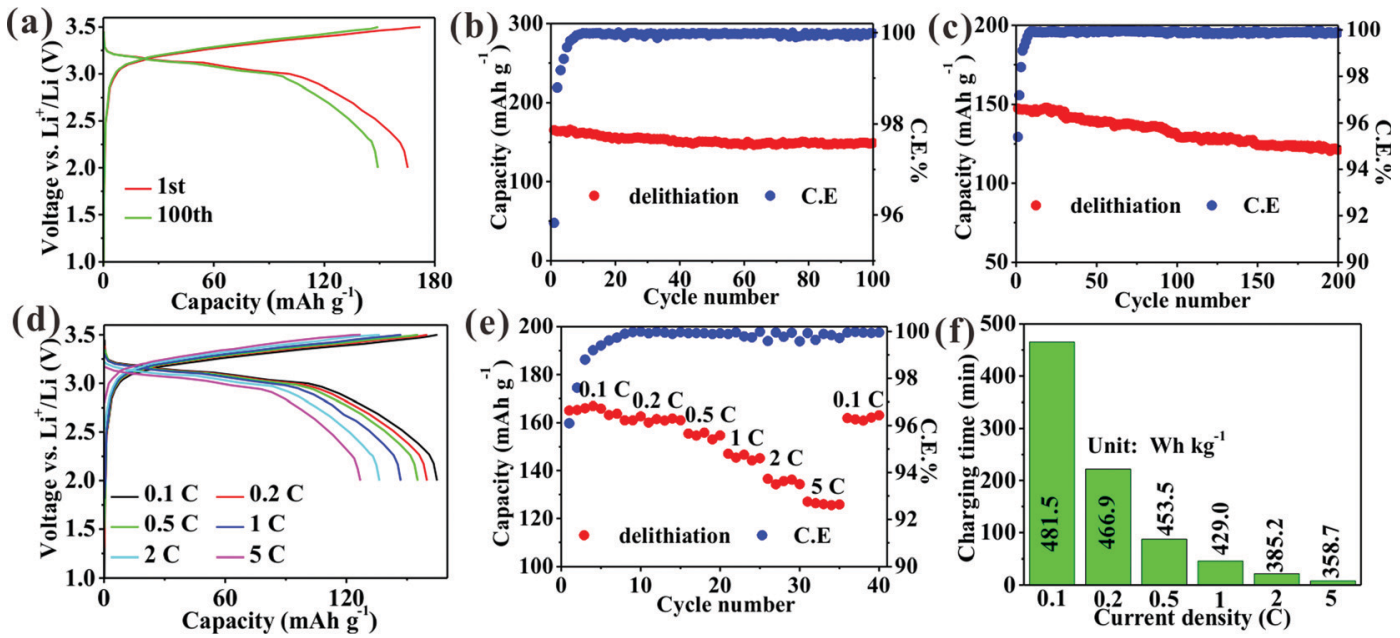

Fig. 5 Electrochemical performances of full cells. (a) Charge/discharge curves at $0.1 \mathrm{C}$, (b and c) cycling performances at 0.1 and $1 \mathrm{C}$, respectively, (d) voltage profiles at various current densities, (e) rate curves, and (f) charge time at different rates.

structure at the nanoscale, highly mesoporous structure, and N,O co-doped C (Fig. 4e). Especially, $\mathrm{N}$ and $\mathrm{O}$ atoms effectively bridge Ge nanocrystals and $\mathrm{C}$ via the interfacial bichemical bonds of $\mathrm{Ge}-\mathrm{O}-\mathrm{C}$ and $\mathrm{Ge}-\mathrm{N}-\mathrm{C}$ (Fig. 4e) to enhance the robustness of the composite structure and accelerate the transport rate of $\mathrm{Li}^{+}$ into the composite, thus ensuring outstanding $\mathrm{Li}^{+}$storage performances.

A full cell with LFP as the cathode delivers a high capacity of $165.3 \mathrm{~mA} \mathrm{~h} \mathrm{~g}^{-1}$ with a capacity retention of $90.2 \%$ after 100 cycles and an average CE of $99.93 \%$ at $0.1 \mathrm{C}$ (Fig. $5 \mathrm{a}$ and b) and $147.5 \mathrm{~mA} \mathrm{~h} \mathrm{~g}^{-1}$ with a capacity retention of $81.9 \%$ after 200 cycles and an average CE of $99.90 \%$ at 1C (Fig. 5c). Such a high capacity retention and CE imply the excellent cyclability and reversibility of the full cell. Clearly, a discharge platform appears from 3.0 to $3.2 \mathrm{~V}$ (Fig. 5a) to produce a high nominal voltage of $3.1 \mathrm{~V}$. Remarkably, a series of high capacities of $165.1,160.1,155.5,147.1,136.5$, and $127.1 \mathrm{~mA} \mathrm{~h} \mathrm{~g}^{-1}$ are obtained at 0.1, 0.2, 0.5, 1, 2, and 5C, respectively, (Fig. 5d and e). Such a high capacity of $127.1 \mathrm{~mA} \mathrm{~h} \mathrm{~g}^{-1}$ is achieved at 5C, which confirms the striking rate capability of the full cell. The calculated gravimetric/volumetric energy densities (introduced in detail in ESI $\dagger$ ) at $0.1 \mathrm{C}$ are $481.5 \mathrm{~W} \mathrm{~h} \mathrm{~kg}^{-1} / 1019.1 \mathrm{~W} \mathrm{~h} \mathrm{~L}^{-1}$ higher than those of full cells of graphite/LFP, ${ }^{32}$ graphite/ $\mathrm{LiCoO}_{2}(\mathrm{LCO}),{ }^{33} \mathrm{SiO}_{x} / \mathrm{C} / \mathrm{LCO},{ }^{34}$ and $\mathrm{Si} / \mathrm{C} / \mathrm{LCO}{ }^{35}$ Importantly, the energy density of $358.7 \mathrm{~W} \mathrm{~h} \mathrm{~kg}^{-1}$ at $5 \mathrm{C}$ obtained within a charging time of less than 8 minutes (Fig. $5 \mathrm{f}$ ) reached $74.5 \%$ of the energy density obtained at $0.1 \mathrm{C}$, which has been not reported previously and shows the promising practicability of the $\mathrm{Ge} / \mathrm{C}$ anode for next-generation fast-charging high-energydensity LIBs.

\section{Conclusions}

To conclude, a novel Ge/C nanocomposite was fabricated via the one-step pyrolysis of a mixture of BS and DMF in a sealed vessel. The $\mathrm{Ge} / \mathrm{C}$ nanocomposite possesses a unique structure in that Ge nanocrystals $(\sim 20 \mathrm{~nm})$ are evenly distributed into a highly mesoporous N,O co-doped carbon matrix to form numerous phase boundaries, in which $\mathrm{N}$ and $\mathrm{O}$ atoms tightly bridge $\mathrm{Ge}$ and $\mathrm{C}$ via vast interfacial chemical bonds of $\mathrm{Ge}-\mathrm{N}-\mathrm{C}$ and $\mathrm{Ge}-\mathrm{O}-\mathrm{C}$. The structure endows the $\mathrm{Ge} / \mathrm{C}$ with a high capacity of $1607.8 \mathrm{~mA} \mathrm{~h} \mathrm{~g}^{-1}$, a remarkable cyclability $(94.4 \%$ capacity retention after 3000 cycles at $5 \mathrm{C}$ ), and a striking rate capability (491.7 $\mathrm{mA} \mathrm{h} \mathrm{g}^{-1}$ at 20C) as an LIB anode in half cells. Remarkably, a high energy density of $481.5 / 358.7 \mathrm{~W} \mathrm{~h} \mathrm{~kg}^{-1}$ at $0.1 / 5 \mathrm{C}$, a high volumetric energy density of $1019.1 \mathrm{Wh} \mathrm{L}^{-1}$, and excellent cyclability (capacity retention of $81.9 \%$ after 200 cycles at 1C) were obtained in full cells.

\section{Conflicts of interest}

There are no conflicts of interest to declare.

\section{Acknowledgements}

Meisheng Han acknowledges support from the Guangdong Basic and Applied Basic Research Foundation (2020A1515110762). Technical support from the Ceshigo Research Service agency for the TEM, www.ceshigo.com is gratefully acknowledged. Thanks to Eric Zhang from ZhongKe BlueOcean (Tianjin) Technology Co., Ltd. (www.zkbotj.com) for the SEM and BET experimental analysis. Thanks to Jiaojiao Fang from the Shiyanjia Lab (www.shiyanjia.com) for the SEM analysis.

\section{References}

1 J. Liu, Z. Bao, Y. Cui, E. J. Dufek, J. Goodenough, P. Khalifah, Q. Li, B. Liaw, P. Liu, A. Manthiram, Y. Meng, V. R. Subramanian, M. Toney, V. Viswanathan, M. Whittingham, J. Xiao, W. Xu, J. Yang, X. Yang and J. Zhang, Nat. Energy, 2019, 4, 180-186.

2 Y. Liu, Y. Zhu and Y. Cui, Nat. Energy, 2019, 4, 540-550. 
3 J. Dahn, T. Zheng, Y. Liu and J. Xue, Science, 1995, 270, 590-593.

4 M. Yoshio, H. Wang and K. Fukuda, Angew. Chem., Int. Ed., 2003, 42, 4203-4206.

5 C. Chan, H. Peng, G. Liu, K. McIlwrath, X. Zhang, R. A. Huggins and Y. Cui, Nat. Nanotechnol., 2008, 3, 31-35.

6 S. Choi, J. Kim, N.-S. Choi, M. Kim and S. Park, ACS Nano, 2015, 9, 2203-2212.

7 M. Han, Y. Mu and J. Yu, Energy Technol., 2019, 8, 201901202.

8 M. Han and J. Yu, J. Power Sources, 2019, 414, 435-443.

9 M. Han and J. Yu, Energy Technol., 2019, 7, 1900084.

10 M. Han, Y. Mu, F. Yuan, J. Liang, T. Jiang, X. Bai and J. Yu, J. Mater. Chem. A, 2020, 8, 3822-3833.

11 D. McNultya, H. Geaneya, D. Buckleya and C. O'Dwyera, Nano Energy, 2018, 43, 11-21.

12 M. Han, Y. Mu and J. Yu, Mater. Adv., 2020, 1, 421-429.

13 M. Han, Z. Lin and J. Yu, J. Mater. Chem. A, 2019, 7, 4804-4812.

14 I. Kim, S.-W. Park and D.-W. Kim, Chem. Eng. J., 2019, 375, 122033.

15 J. Hwang, C. Jo, M. Kim, J. Chun, E. Lim, S. Kim, S. Jeong, Y. Kim and J. Lee, ACS Nano, 2015, 9, 5299-5309.

16 F. Pantò, Y. Fan, S. Stelitano, E. Fazio, S. Patanè, P. Frontera, P. Antonucci, N. Pinna and S. Santangelo, Adv. Funct. Mater., 2018, 28, 1800938.

17 Y. Wang, S. Luo, M. Chen and L. Wu, Adv. Funct. Mater., 2020, 30, 2000373.

18 J. Graetz, C. Ahn, R. Yazami and B. Fultz, J. Electrochem. Soc., 2014, 151, 698-702.

19 M.-H. Park, Y. Cho, K. Kim, J. Kim, M. Liu and J. Cho, Angew. Chem., Int. Ed., 2011, 50, 9647-9650.

20 H. Kim, Y. Son, C. Park, J. Cho and H. Choi, Angew. Chem., Int. Ed., 2013, 52, 5997-6001.
21 D. Xue, S. Xin, Y. Yan, K. Jiang, Y. Yin, Y. Guo and L. Wan, J. Am. Chem. Soc., 2012, 134, 2512-2515.

22 B. Wang, J. Jin and Z. Wen, Chem. Eng. J., 2018, 360, 1301-1309.

23 K. Huo, L. Wang, C. Peng, X. Peng, Y. Li, Q. Li, Z. Jin and P. Chu, J. Mater. Chem. A, 2016, 4, 7585-7590.

24 D. Youn, N. Patterson, H. Park, A. Heller and C. Mullins, ACS Appl. Mater. Interfaces, 2016, 8, 27788-27794.

25 E. Lewin, M. Parlinska-Wojtan and J. Patscheider, J. Mater. Chem., 2012, 22, 16761-16773.

26 M. Han, Y. Mu, F. Yuan, X. Bai and J. Yu, J. Power Sources, 2020, 465, 228206.

27 H. Guo, B. Ruan, L. Liu, L. Zhang, Z. Tao, S. Chou, J. Wang and H. Liu, Small, 2017, 13, 1700920.

28 Y. Son, M. Park, Y. Son, J.-S. Lee, J.-H. Jang, Y. Kim and J. Cho, Nano Lett., 2014, 14, 1005-1010.

29 X. Liu, S. Huang, S. T. Picraux, J. Li, T. Zhu and J. Huang, Nano Lett., 2011, 11, 3991-3997.

30 M. Han, Z. Lin, X. Ji, Y. Mu, J. Li and J. Yu, Mater. Today Energy, 2020, 17, 100445.

31 H. Kim, W. Choi, J. Yoon, J. Um, W. Lee, J. Kim, J. Cabana and W.-S. Yoon, Chem. Rev., 2020, 120, 6934-6976.

32 Y. Mu, M. Han, J. Li, J. Liang and J. Yu, Carbon, 2021, 173, 477-484.

33 M. Ko, S. Chae, J. Ma, N. Kim, H.-W. Lee, Y. Cui and J. Cho, Nat. Energy, 2016, 1, 1-8.

34 Z. Liu, Y. Zhao, R. He, W. Luo, J. Meng, Q. Yu, D. Zhao, L. Zhou and L. Mai, Energy Storage Mater., 2019, 19, 299-305.

35 H. J. Kwon, J.-Y. Hwang, H.-J. Shin, M.-G. Jeong, K. Y. Chung, Y.-K. Sun and H.-G. Jung, Nano Lett., 2020, 20, 625-635. 